\title{
Risperidone regulates Dopamine D2-like receptors expression in rat brain in a time-dependent manner
}

\author{
Ni Peiyan ${ }^{\star, \star \star}$ \\ Liang Linhui ${ }^{*}, \star *$ \\ Wang Yingcheng ${ }^{\star * \star *}$ \\ Wei Jinxue ${ }^{\star, \star \star}$ \\ Gu Xiaochu*,** \\ Zhao liansheng, ${ }^{*, * *}$ \\ Ma Xiaohong ${ }^{\star, * \star}$ \\ Li Tao*,**
}

* Psychiatric Laboratory and Department of Psychiatry, West China Hospital, Sichuan University, Chengdu, 610041, P.R.

** State Key Laboratory of Biotherapy, West China Hospital, Sichuan University,

Chengdu, 610041, P.R.

CHINA

\begin{abstract}
Background and Objectives: Antipsychotics can elicit dopamine supersensitivity by up-regulation of D2-like receptors (DRD2, DRD3, and DRD4) expression. Nevertheless, the expression profile of dopamine D2-like receptors in different brain regions and peripheral blood mononuclear cells (PBMCs), and changes following risperidone administration were still unclear. In this study, we would investigate the expression of D2-like receptors mRNA in different brain regions and the peripheral blood mononuclear cells (PBMCs) in rats after 2, 6 weeks risperidone administration.

Methods: The experimental rats were given risperidone $(0.25 \mathrm{mg} / \mathrm{kg} / \mathrm{day}$, i.p. $)$, and the control rats were given $0.9 \% \mathrm{NaCl}$. The rats were sacrificed at 0 week, 2 weeks and 6 weeks after the drug administration. Expression of the dopamine D2-like receptors was quantified by Real-time PCR method.

Results: Dopamine D2-like receptors expressed in all the examined regions of rat brain. Their expression significantly increased 2 weeks after risperidone administration in different brain regions. However, the changed expression of DRD2 and DRD3 turned back to the basal level 6weeks later, while the increased DRD4 expression remained in left parietal cortex. Meanwhile, DRD2 and DRD3 but not DRD4 expressed in PBMCs, however, the risperidone could not affect their expression.

Conclusions: The risperidone could change the dopamine D2-like receptors expression in a time-dependent manner in different brain regions, which might guide the clinical use in the near future.
\end{abstract}




\section{Introduction}

As reported, long-term use of antipsychotic is known to elicit dopamine super sensitivity through up-regulation of $\mathrm{D} 2$ receptor expression $^{1,2}$. Risperidone, as a new generation of antipsychotic drugs, is widely used in clinical treatment of mental disorders based on the fact that it can relieve the positive symptoms and reduce the side effects ${ }^{3}$. Risperidone is a selective monoaminergic antagonist ${ }^{4}$, but the exact underlying mechanism of risperidone on the dopamine D2-like receptors is not entirely clear.

Dopamine receptors are membrane-bound receptors that belong to a G-protein coupled receptor family ${ }^{5}$ and consist of five wellknown subtypes, namely, DRD1, DRD2, DRD3, DRD4, and DRD5. These receptors can be grouped into two classes, namely, the D1-like family receptors (DRD1 and DRD5) and D2-like family receptors (DRD2, DRD3 and DRD4) according to their biochemical and pharmacological properties ${ }^{6}$. Numerous studies have focused on the biology of abnormal dopamine D2-like receptors as an underlying cause of mental disorders. In terms of the genetic point of view, the variants in dopamine D2-like receptors genes have been linked to many kinds of mental disorders, such as schizophrenia ${ }^{7-9}$. Moreover, the dopamine receptor gene polymorphism was also consisted with the response to antipsychotic treatment ${ }^{7-9}$. With regard to molecular and biochemical properties, the dopamine receptors binding and expression are abnormal in postmortem tissues of patients with various disorders such as schizophrenia ${ }^{10,11}$.

Risperidone can relieve psychotic symptoms via dopamine D2 receptor antagonism ${ }^{1}$. In schizophrenia, risperidone could increase D2 dopamine receptor occupancies, while ranged from 50 to $92 \%$ in striatal and 4 to $95 \%$ in the different extra striatal ${ }^{12}$. In addition, the clinical effect of antipsychotic drugs corresponds to the time course of the altered genes expression in the brain ${ }^{13}$. Risperidone treatment (12 days) in wild type mice can decrease dopamine D2 receptor gene expression in the prefrontal cortex (PFC), and the dorsal raphe $(\mathrm{DR})^{14}$. Also, D2 receptor mRNA and protein expression were increased in both the medial preoptic area (MPOA), and the paraventricular nucleus (PVN) after 3 weeks' risperidone $\operatorname{administration}^{15}$.

In this study, we would investigate the expression of DRD2, DRD3, and DRD4 mRNA in different brain regions of rats after 2, 6 weeks risperidone administration. In addition, we also studied the dopamine D2-like family receptors expression profile in rat peripheral blood mononuclear cells (PBMCs), in order to explore if dopamine D2-like family receptors expression in PBMCs would be considered as convenient peripheral biomarkers to reflect the probable changes of dopamine D2-like receptors expression in the corresponding brain regions. We hope that this study may help understand the biological mechanism of the therapeutic effect of risperidone and guide its clinical use.

\section{Experimental procedures}

\section{Animals}

We purchased the rats from the Experimental Animals Center of Sichuan Province, China. All animals were housed and maintained in accordance with the policies of Institutional Animal Care and Use Committee of Laboratory Animal Care of West china, Sichuan University. To avoid the probable confounding contributions from the oestrous cycle, male Wistar rats weighing 280 to 300 $\mathrm{g}$ were housed in a clear plastic cage with unrestricted access to food and water. The ani- 
mals laboratory temperature was $20 \pm 2^{\circ} \mathrm{C}$ and humidity was $60 \pm 5 \%$ with a $12 \mathrm{~h}: 12 \mathrm{~h}$ light-dark cycle (lights on at 7:00 am).

\section{Drug administration}

Male Wistar rats $(n=40)$ were assigned to five groups ( $\mathrm{n}=8$ per group). Risperidone (Beijing Gaobo Pharm-Chemicals Tech.Co., Ltd) was dissolved in a few drops of glacial acetic acid and diluted in sterile $0.9 \%$ physiological saline, titrated to a final $\mathrm{Ph}=6$ with $6 \mathrm{~N} \mathrm{NaOH}^{15}$. At the beginning of the drug administration, the baseline group (0 week) were sacrificed. Two experimental groups were given risperidone $(0.25 \mathrm{mg} / \mathrm{kg})$ once daily in a concentration of $1 \mathrm{mg} / \mathrm{ml}$. The control rats were given the same constituent except risperidone. All the solutions were administered via intraperitoneal injection (i.p.). During the experiment, all rats were in good condition. No abnormality was observed with regard to weight, hair, and feces.

\section{Dopamine D2-like receptors expression}

The baseline group was sacrificed without any processing and the other groups were sacrificed $24 \mathrm{~h}$ later at the end of solution administration. First, rats were anesthetized $(2 \mathrm{ml} / \mathrm{kg}$ ) using chloral hydrate oral solution (West China Hospital, Sichuan University, China), and blood was collected from heart. Then 330ul blood and $1 \mathrm{ml}$ Trizol LS (Invitrogen, USA) were mixed in $1.5 \mathrm{ml}$ centrifuge tube and stored at $-80^{\circ} \mathrm{C}$ until processed following Trizol LS manual. After that, rats were decapitated and the brains were quickly removed from the skull to dissect the following regions: hippocampus, left and right frontal cortex, left and right parietal cortex, and left and right temporal lobe. The dissec- tion was performed on ice. All the regions were immediately frozen in liquid nitrogen and stored at $-80^{\circ} \mathrm{C}$ until being processed.

The total RNA of the collected brain regions was isolated using Trizol reagent (Invitrogen, USA) and then retro-transcribed to cDNA using the ReverTra Ace qPCR RT Kit (TOYOBO, Japan). The rat specific oligonucleotide primers were designed using Beacon Designer 7.7 software and synthesized using Invitrogen as the following:

GAPDH, Sense Primer 5'-ATGACAATGAATATGGCTACAG

Anti-sense Primer: 5'-CTCTTGCTCTCAGTATCCTT

DRD2, Sense Primer:

\section{5'-CAACAATACAGACCAGAATGAG}

Anti-sense Primer:

5'-CAGCAGAGTGACGATGAA

DRD3, Sense Primer:

\section{5'-ACCACCACCAACTACCTA}

Anti-sense Primer:

5'-ACCTGTCACCTCCAAGTA

DRD4, Sense Primer: 5'-TTGCCTCTCTTTGTCTACTC

Anti-sense Primer:

\section{5'-GCACAGGTTGAAGATGGA}

The real-time PCR was conducted following the manual of SsoFast EvaGreen ${ }^{\mathrm{TM}}$ Supermix (BIO-RAD, USA). The relative DRD2, DRD3, and DRD4 mRNA expressions were performed using the $\mathrm{iQTM}^{5}$ Real-Time PCR Sequence Detector System (BIO-RAD). The PCR cycling parameters were: $95^{\circ} \mathrm{C}$ for 30 sec, followed by 40 cycles at $95^{\circ} \mathrm{C}$ for $5 \mathrm{sec}$, and $60^{\circ} \mathrm{C}$ for 10 second. Data were normalized to the endogenous reference gene (GAPDH), and the fold change in target gene mRNA abundance was determined using the $2^{-\Delta \Delta C t}$ method. 


\section{Statistical Analysis}

All statistical analyses were performed using SPSS16.0. Differences among groups were analysed using ANOVA followed by post-hoc Dunnett's t-test. Significant differences were defined as those with a p-value smaller than 0.05 .

\section{Results}

\section{Expression Profile of Dopamine D2-Like Receptors in the rat brain and PBMCs}

The mRNA level expression pattern of dopamine D2-like receptors in different brain regions and PBMCs of rats was shown in Fig. 1. The dopamine D2-like receptors all expressed in the tested brain regions of hippocampus, frontal cortex, parietal cortex, and temporal lobe. Meanwhile, the expression level of dopamine D2-like receptors varied in all the tested brain regions. The DRD2 expressed highly in the left frontal cortex and temporal lobe, and DRD3 expression was relatively high in the right temporal lobe. DRD4 highly expressed in the right temporal lobe, and expressed higher than in the left temporal lobe (Fig. 1C). We also tested the expressions of DRDs in rat PBMCs. As shown in Fig. 1, DRD2 and DRD3 expressed relatively highly in PBMCs (Fig. 1A and 1B), while DRD4 did not express at all in PBMCs (Fig. 1C).

\section{Time-dependent expressions of DRD2 after risperidone administration}

The effects of risperdone on DRD2 expression in different brain regions and PBMCs in rats were presented in Fig. 2. As shown in Fig. 2D, DRD2 expression in the right parietal cortex increased significantly $(\mathrm{p}=0.001)$ after two weeks of risperdone administration. Meanwhile, the DRD2 expression in the right parietal cortex of risperidone-treated group was significantly higher than which of the control group $(p<0.001)$. Nevertheless, at the end of the sixth week of risperdone administration, the difference of $\mathrm{D} 2$ receptor expression in the right parietal cortex between the two groups disappeared. In addition, in other brain regions and PBMCs, DRD2 expression did not differ between the risperi-

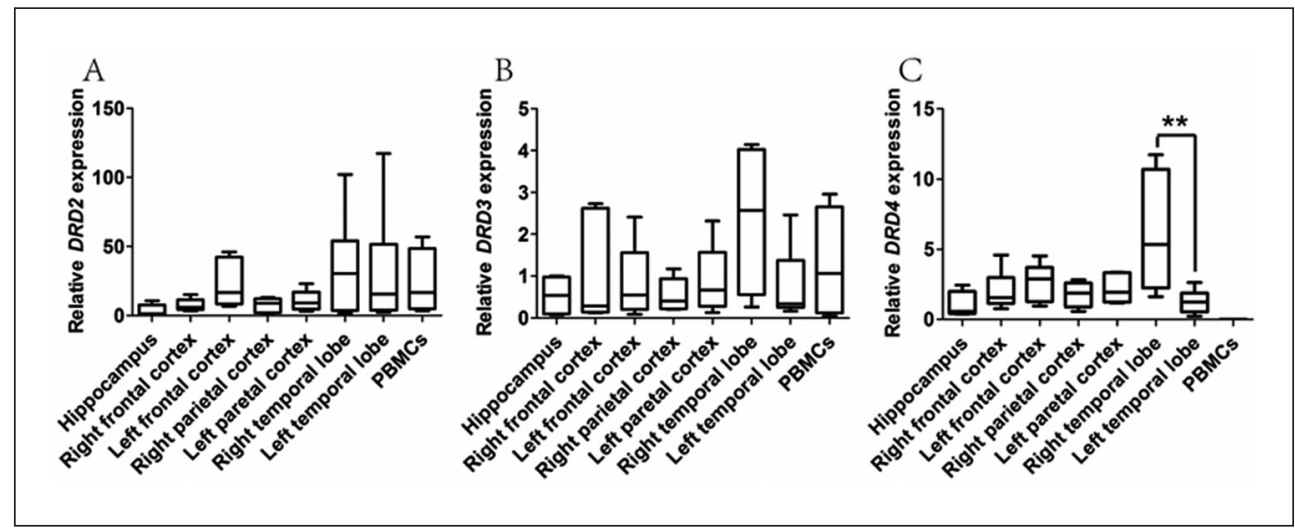

Figure 1. Expression profile of dopamine D2-like receptors in hippocampus, left and right frontal cortex, left and right temporal lobe, left and right parietal cortex, and PBMCs. 


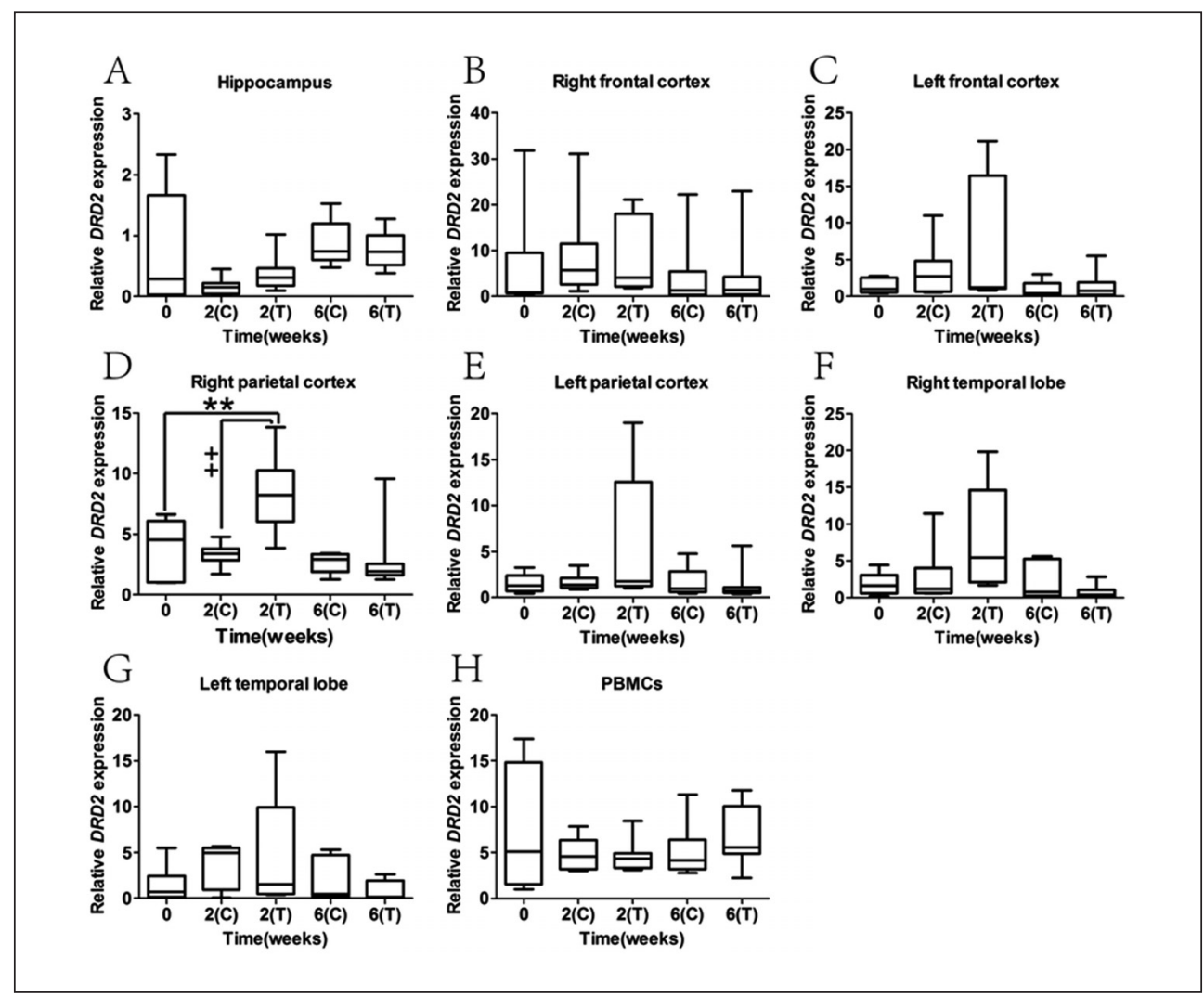

Figure 2. Expression of DRD2 mRNA in rat brain and PBMCs after 2 and 6 weeks of risperidone administration. Relative DRD2 expression levels were normalized by the housekeeping gene, GAPDH. 0: base-line without administration; $\mathrm{C}$ : control group $(0.9 \% \mathrm{NaCl})$; T: risperidone-treatment group. $* * \mathrm{p}<0.01$ vs. base-line group, $++\mathrm{p}<0.01$ vs. control group.

done-treated group and the control group after two weeks and six weeks of treatment (Fig. 2A-C, and E-H). In conclusion, risperidone might regulate the DRD2 expression intently in the right parietal cortex during the twoweek risperidone administration.

\section{Time-dependent expressions of DRD3 after risperdone administration}

Fig. 3 presented the effects of risperdone on DRD3 in different brain regions and
PBMCs. After two weeks of risperdone administration, the DRD3 expression significantly increased in the right parietal cortex (Fig. 3D, p < 0.001) and left parietal cortex (Fig. 3E, p = 0.001). Meanwhile, the DRD3 expression in the right parietal cortex and the left parietal cortex was significantly higher than which in the control group ( $\mathrm{p}=$ 0.005 and $p=0.001$, respectively). After six weeks of administration, the DRD3 expression in the right parietal cortex and the left parietal cortex in both groups restored to the basal level. In other brain regions and PBMCs, DRD3 expression did not differ be- 

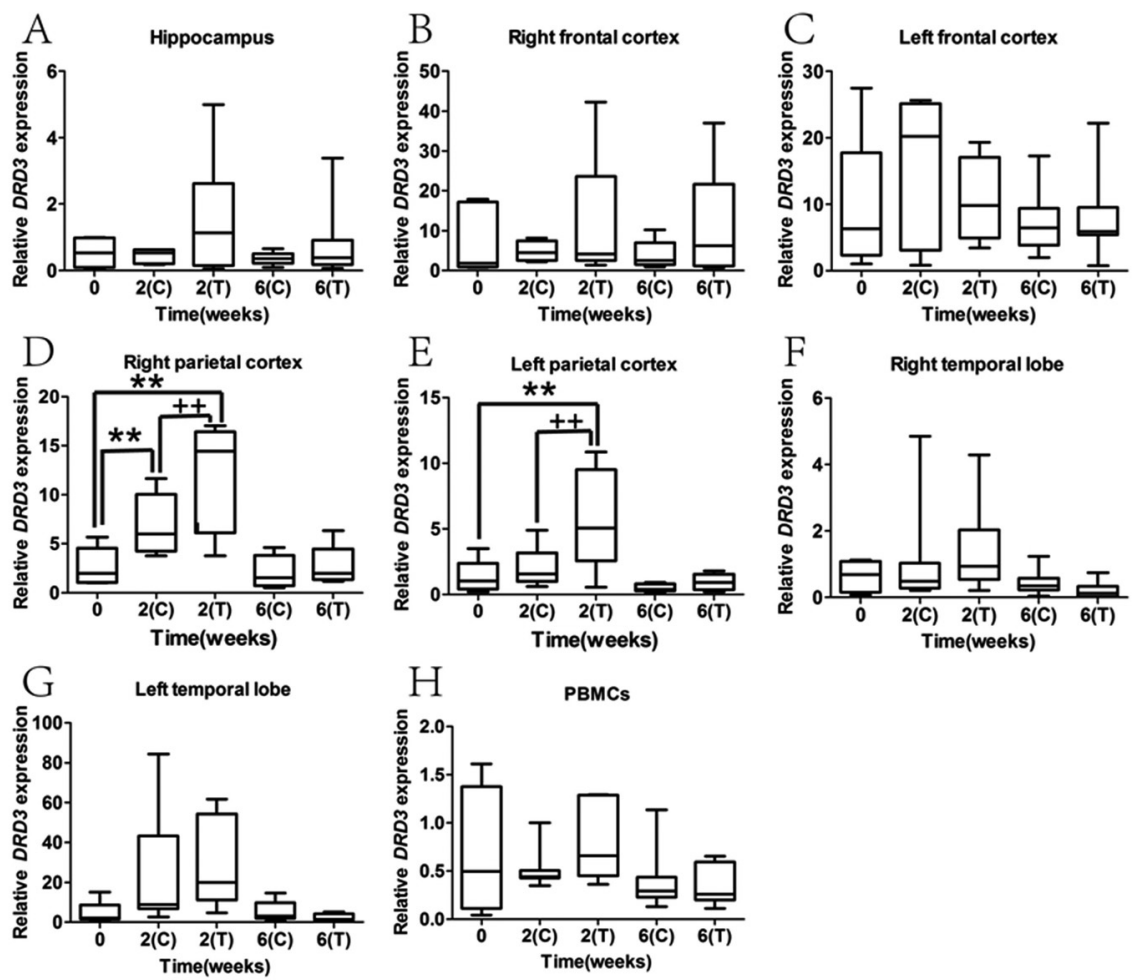

Figure 3. Expression of DRD3 mRNA in rat brain and PBMCs after 2 and 6 weeks of risperidone administration. Relative DRD3 expression levels were normalized by the housekeeping gene, GAPDH. Data were relative to GAPDH mRNA. 0: base-line without administration; C: control group $(0.9 \% \mathrm{NaCl})$; T: risperidone-treatment group. $* \mathrm{p}<0.05,{ }^{* *} \mathrm{p}<0.01$ vs. base-line group, $++\mathrm{p}<0.01$ vs. control group.

tween risperidone-treated group and control group at both predetermined time points (Fig. 2A-C, and F-H). In general, DRD3 expression was up-regulated only in the parietal cortex by acute risperidone administration.

\section{Time-dependent expressions of DRD4 after risperidone administration}

After two weeks of risperidone administration, DRD4 expression significantly increased in all the tested brain regions except the right temporal lobe (Fig. 4F). Meanwhile, DRD4 expression in all tested brain regions except hippocampus of the risperidonetreated group was significantly higher than that in the control group (Fig. 4A). Six weeks later, DRD4 expression kept increased level only in the left parietal $(\mathrm{p}=0.025)$ and restored to the untreated level in all the other brain regions. Overall, DRD4 expression was widely up-regulated in the brain by acute risperidone administration, but could remain effective for up to six weeks only in the left parietal cortex (Fig. 4E). 


\section{No changes of dopamine D2-like receptors expressions in PBMCs after risperidone administration}

As shown in Fig. 1, DRD2 and DRD3 expressed relatively highly in PBMCs. However, their expressions of mRNA level did not present any changes after 2-week or 6-week risperidone administration (data not shown).

\section{Discussion}

The present study provided evidence that the dopamine D2-like receptors widely expressed in rat hippocampus, frontal cortex, parietal cortex, and temporal lobe by realtime PCR method. Our data are consistent with findings of previous studies that DRD2 expression was found in cortical areas ${ }^{2,16,17}$, and DRD3 were observed in various cortical areas ${ }^{18,19}$, while the DRD4 receptor was documented expression in frontal cortex ${ }^{9}$. In addition to frontal cortex we also found DRD4 expression in other cortical areas such as parietal cortex, and temporal lobe, which may result from the high sensitivity of our experimental performance. We found that the expression of dopamine D2-like receptors were not the same in different brain regions, not even in the same brain region of different cerebral hemispheres, which might provide specified biological function in different brain regions and cerebral hemispheres.

Also, we demonstrated that risperidone could regulate the dopamine D2-like receptors in rat brain. DRD2 expression increased in the right parietal cortex after being treated with risperidone for 2 weeks. In previous studies, the changed expression of DRD2 was reported in different brain regions, such as decrease in prefrontal cortex and locus coeruleus (15mg/kg, 12 days $)^{20}$ and increase in medial preoptic area and the paraventricular nucleus $(0.25 \mathrm{mg} / \mathrm{kg}, 21 \text { days })^{15}$. To our knowledge, so far no study has reported DRD2 expression in the right parietal cortex after risperidone treatment. DRD3 was upregulated by typical antipsychotics such as clozapine and sulpiride ${ }^{21}$, but the effect of risperidone on DRD3 expression has not been reported. In our study, the DRD3 expression was up-regulated only in the parietal cortex after 2 weeks of acute risperidone administration. With regard to DRD4 expression, risperidone could up-regulate DRD4 expression in frontal cortex, parietal cortex, and temporal lobe. This result verified a previous conclusion that the $\mathrm{D} 4$ receptor mRNA was up-regulated in cerebral cortex by risperidone $22-24$. As a matter of fact, only slight increases of DRD3 expression in right parietal cortex (Fig. 3D) and DRD4 expression in hippocampus and right temporal lobe (Fig. 4A and Fig. 4F) were observed after two weeks of sodium chloride administration, which may be caused by the operation process.

Moreover, changes in the expression of dopamine D2-like receptors were different after 0,2 , and 6 weeks of risperidone administration. DRD2 expression increased in the right parietal cortex after 2 weeks of risperidone administration but restored to the basal level when the examination time up to 6 weeks. DRD3 expression was up-regulated in parietal cortex with 2-week but not 6-week risperidone administration. The DRD4 mRNA was up-regulated in frontal cortex, parietal cortex, and temporal lobe by risperidone after 2 weeks of risperidone administration but only in left parietal cortex after 6 weeks. All the results show that risperidone can regulate the dopamine receptors in a time-dependent manner, which might be attributed to the different efficacy of acute and chronic risperidone administration ${ }^{25}$. The analogous time-dependent receptor expres- 

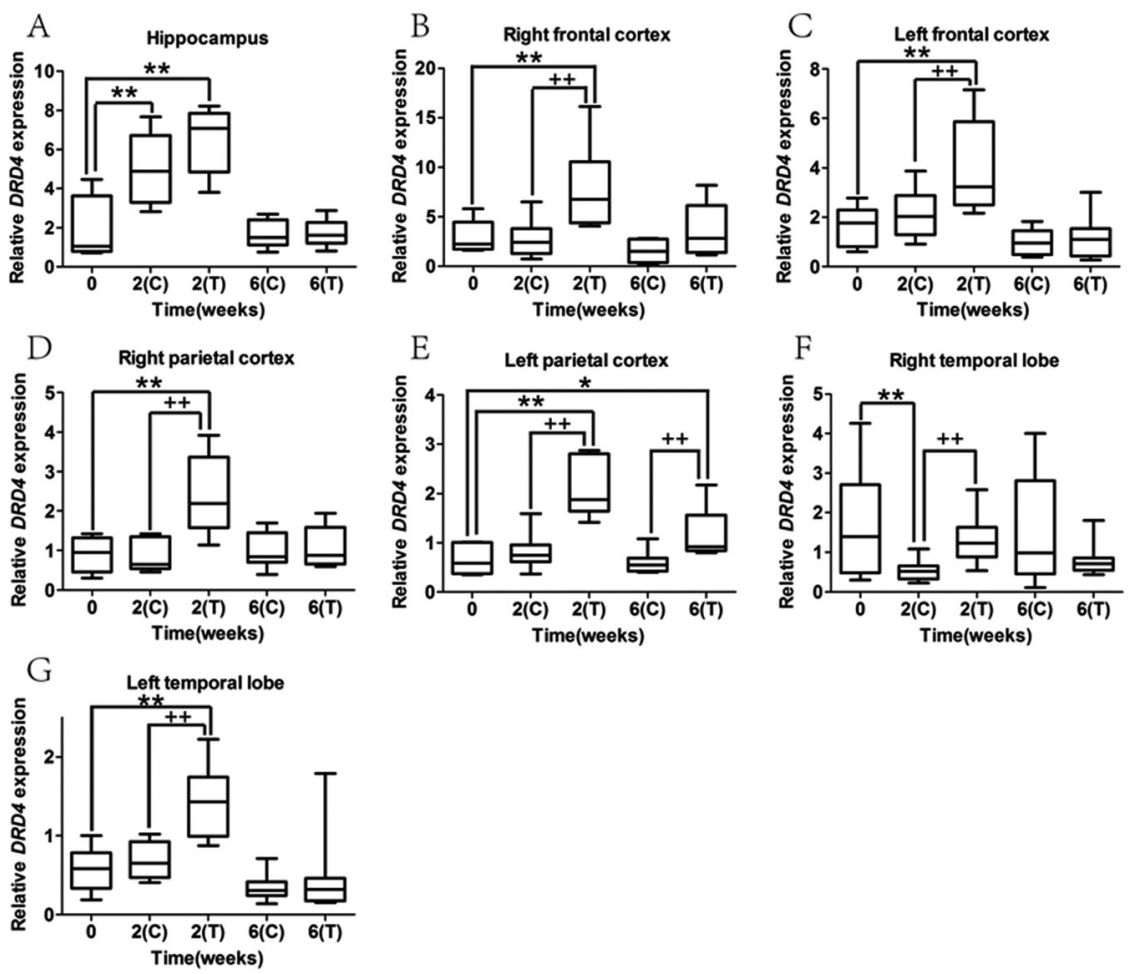

Figure 4. Expression of DRD4 in rat brain after 2 and 6 weeks of risperidone administration. Relative DRD4expression levels were normalized by the housekeeping gene, GAPDH. 0: base-line without administration; $\mathrm{C}$ : control group $(0.9 \% \mathrm{NaCl})$; T: risperidone-treatment group. $* \mathrm{p}<0.05, * * \mathrm{p}<0.01$ vs. base-line group, $++\mathrm{p}<0.01$ vs. control group.

sion was found in many researches. For example, risperidone can decrease 7 nicotinic receptor expression in the basal forebrain and prefrontal cortex after a 90-days (but not 15-day) risperidone administration ${ }^{26}$. Furthermore, the mice presented changes in neurotrophin and neurotransmitter level ${ }^{27-29}$ and protracted deficits in the performance of animal behavior tests in a time-dependent manner after risperidone administration ${ }^{27,29-31}$. Moreover, time-dependent effects of antipsychotic on gene expression or neurotransmitter dopamine turn-over was also found in clinical psychiatric treatment ${ }^{32,33}$.
In this study, we demonstrated that DRD2 and DRD3 expressed in PBMCs using Quantitative Real-time PCR Assay. As reported, DRD3 expressed in the rat lymphocytes through reverse transcriptase-polymerase chain reaction ${ }^{34}$ and Receptor Binding Assay $^{35}$. Up to now, no study has suggested that DRD2 expressed in rat PBMCs. The discrepancy among these conclusions on DRD2 expression might be attributed to the fact that the sensitivity of Real-Time PCR is higher than the Receptor Binding Assay and reverse transcriptase-polymerase chain reaction ${ }^{36}$. Both Receptor Binding Assay and reverse 
transcriptase-polymerase chain reaction presented that DRD4 did not express in rat PBMCs $^{34,35}$, which was consistent with our study in which we also verified this point using Real-time PCR Assay.

The expression of dopamine receptors in PBMCs changed in patients with schizophrenia and those with bipolar disorders ${ }^{37-39}$, and which was also affected by cognitive response following dopamine agonist treatment (opioid addiction) or the personality trait of persistence ${ }^{40-42}$. To our knowledge, no study has reported the effect of risperidone on dopamine D2-like receptors expression in rat PBMCs. If dopamine D2-like family receptors expression in PBMCs changed correspondingly to different brain regions in a time course after risperidone administration, they would be considered as convenient biomarkers to predict the relevant changes in brain, which may provide a new window for objective medication guide clinically. However, our results demonstrated that risperidone could not affect the expression of DRD2 or DRD3 in rat PBMCs. Whether these negative finding is a fact or just a fuzzy seemingly due to the limited experimental design might need further investigation. For this purpose, optimized designs with appropriate drug concentration gradient, rational time interval, and precise dissection are to be expected. Furthermore, the over-reliance on male animals in preclinical research might obscure sex differences that could guide clinical studies ${ }^{43}$, so female Wistar rats should be included to balance the potential influence of gender in our future work.

\section{Acknowledgements}

The study was funded by National Natural Science Foundation of China (81071089) and
Specialized Research Fund for the Doctoral Program of Higher Education (2013018112 0032).

\section{References}

1. Lieberman JA, Bymaster FP, Meltzer HY, Deutch AY, Duncan GE, Marx CE, et al. Antipsychotic drugs: Comparison in animal models of efficacy, neurotransmitter regulation, and neuroprotection. Pharmacological reviews. 2008; 60: $358-403$.

2. Seeman P, Schwarz J, Chen JF, Szechtman H, Perreault M, McKnight GS, et al. Psychosis pathways converge via D2high dopamine receptors. Synapse. 2006; 60: 319-46.

3. Davis KL, Stewart DG, Friedman JI, Buchsbaum M, Harvey PD, Hof PR, et al. White matter changes in schizophrenia: Evidence for myelin-related dysfunction. Archives of general psychiatry. 2003; 60: 443-56.

4. Tzavara ET, Davis RJ, Perry KW, Li X, Salhoff C, Bymaster FP, et al. The CB1 receptor antagonist SR141716A selectively increases monoaminergic neurotransmission in the medial prefrontal cortex: Implications for therapeutic actions. Br J Pharmacol. 2003; 138: 544-53.

5. Tan S, Hermann B, Borrelli E. Dopaminergic mouse mutants: Investigating the roles of the different dopamine receptor subtypes and the dopamine transporter. International review of neurobiology. 2003; 54: 145-97.

6. Beaulieu JM, Gainetdinov RR, Caron MG. The AktGSK-3 signaling cascade in the actions of dopamine. Trends in pharmacological sciences. 2007; 28: 166-72.

7. Bertram L. Genetic research in schizophrenia: New tools and future perspectives. Schizophrenia bulletin. 2008; 34: 806-12.

8. Parsons MJ, Mata I, Beperet M, Iribarren-Iriso F, Arroyo B, Sainz R, et al. A dopamine D2 receptor gene-related polymorphism is associated with schizophrenia in a Spanish population isolate. Psychiatric genetics. 2007; 17: 159-63.

9. Rondou P, Haegeman G, Van Craenenbroeck K. The dopamine D4 receptor: Biochemical and signalling properties. Cellular and molecular life sciences : CMLS. 2010; 67: 1971-86.

10. Seeman P, Ko F, Jack E, Greenstein R, Dean B. Consistent with dopamine supersensitivity, RGS9 expression is diminished in the amphetamine-treated animal model of schizophrenia and in postmortem schizophrenia brain. Synapse. 2007; 61: 303-9. 
11. Seeman P, Weinshenker D, Quirion R, Srivastava LK, Bhardwaj SK, Grandy DK, et al. Dopamine supersensitivity correlates with D2High states, implying many paths to psychosis. Proceedings of the National Academy of Sciences of the United States of America. 2005; 102: 3513-8.

12. Agid O, Mamo D, Ginovart N, Vitcu I, Wilson AA, Zipursky RB, et al. Striatal vs extrastriatal dopamine D2 receptors in antipsychotic response a double-blind PET study in schizophrenia. Neuropsychopharmacology: Official publication of the American College of Neuropsychopharmacology. 2007; 32: 1209-15.

13. Chen ML, Chen $\mathrm{CH}$. Microarray analysis of differentially expressed genes in rat frontal cortex under chronic risperidone treatment. Neuropsychopharmacology: Official publication of the American College of Neuropsychopharmacology. 2005; 30: 268-77.

14. Ortega-Alvaro A, Aracil-Fernandez A, Garcia-Gutierrez MS, Navarrete F, Manzanares J. Deletion of CB2 cannabinoid receptor induces schizophrenia-related behaviors in mice. Neuropsychopharmacology: Official publication of the American College of Neuropsychopharmacology. 2011; 36: 1489-504.

15. Zhang XR, Wang YX, Zhang ZJ, Li L, Reynolds GP. The effect of chronic antipsychotic drug on hypothalamic expression of neural nitric oxide synthase and dopamine D2 receptor in the male rat. PloS one. 2012; 7: e33247.

16. Sillivan SE, Konradi C. Expression and function of dopamine receptors in the developing medial frontal cortex and striatum of the rat. Neuroscience. 2011; 199: 501-14.

17. Missale C, Nash SR, Robinson SW, Jaber M, Caron MG. Dopamine receptors: from structure to function. Physiological reviews. 1998; 78: 189-225.

18. Sokoloff P, Diaz J, Le Foll B, Guillin O, Leriche L, Bezard E, et al. The dopamine D3 receptor: A therapeutic target for the treatment of neuropsychiatric disorders. CNS \& neurological disorders drug targets. 2006; 5: 25-43.

19. Sokoloff P, Giros B, Martres MP, Andrieux M, Besancon R, Pilon C, et al. Localization and function of the D3 dopamine receptor. Arzneimittel-Forschung. 1992; 42: 224-30.

20. Ortega-Alvaro A, Aracil-Fernández A, García-Gutiérrez MS, Navarrete F, Manzanares J. Deletion of CB2 cannabinoid receptor induces schizophrenia-related behaviors in mice. Neuropsychopharmacology: Official publication of the American College of Neuropsychopharmacology. 2011; 36: 1489-504.

21. Buckland PR, O'Donovan MC, McGuffin P. Clozapine and sulpiride up-regulate dopamine $\mathrm{D} 3$ receptor mRNA levels. Neuropharmacology. 1993; 32: 901-7.

22. Lidow MS, Goldman-Rakic PS. Differential Regulation of D2 and D4Dopamine Receptor mRNAs in the Pri- mate Cerebral Cortexvs. Neostriatum: Effects of Chronic Treatment with Typical and Atypical Antipsychotic Drugs. Journal of Pharmacology and Experimental Therapeutics. 1997; 283: 939-46.

23. Van Craenenbroeck K, Clark SD, Cox MJ, Oak JN, Liu F, Van Tol HH. Folding efficiency is rate-limiting in dopamine D4 receptor biogenesis. Journal of Biological Chemistry. 2005; 280: 19350-7.

24. Tarazi FI, Zhang K, Baldessarini RJ. Dopamine D4 receptors: Beyond schizophrenia. Journal of Receptors and Signal Transduction. 2004; 24: 131-47.

25. Feher LZ, Kalman J, Puskas LG, Gyulveszi G, Kitajka K, Penke B, et al. Impact of haloperidol and risperidone on gene expression profile in the rat cortex. Neurochemistry international. 2005; 47: 271-80.

26. Terry AV, Jr., Gearhart DA. Time dependent decreases in central alpha7 nicotinic acetylcholine receptors associated with haloperidol and risperidone treatment in rats. European journal of pharmacology. 2007; 571: 29-32.

27. Terry AV, Jr., Gearhart DA, Warner S, Hohnadel EJ, Middlemore ML, Zhang G, et al. Protracted effects of chronic oral haloperidol and risperidone on nerve growth factor, cholinergic neurons, and spatial reference learning in rats. Neuroscience. 2007; 150: 413-24.

28. Terry AV, Jr., Hill WD, Parikh V, Evans DR, Waller JL, Mahadik SP. Differential effects of chronic haloperidol and olanzapine exposure on brain cholinergic markers and spatial learning in rats. Psychopharmacology. 2002; 164: 360-8.

29. Terry AV, Jr., Mahadik SP. Time-dependent cognitive deficits associated with first and second generation antipsychotics: Cholinergic dysregulation as a potential mechanism. The Journal of pharmacology and experimental therapeutics. 2007; 320: 961-8.

30. Karl T, Duffy L, O’Brien E, Matsumoto I, Dedova I. Behavioural effects of chronic haloperidol and risperidone treatment in rats. Behavioural brain research. 2006; 171: 286-94.

31. Rosengarten H, Quartermain D. The effect of chronic treatment with typical and atypical antipsychotics on working memory and jaw movements in three- and eighteenmonth-old rats. Progress in neuro-psychopharmacology \& biological psychiatry. 2002; 26: 1047-54.

32. Post RM, Goodwin FK. Time-dependent effects of phenothiazines on dopamine turnover in psychiatric patients. Science. 1975; 190: 488-9.

33. Belzeaux R, Bergon A, Jeanjean V, Loriod B, Formisano-Treziny $\mathrm{C}$, Verrier $\mathrm{L}$, et al. Responder and nonresponder patients exhibit different peripheral transcriptional signatures during major depressive episode. Translational psychiatry. 2012; 2: e185. 
34. Caronti B, Calderaro C, Passarelli F, Palladini G, Pontieri FE. Dopamine receptor mRNAs in the rat lymphocytes. Life sciences. 1998; 62: 1919-25.

35. Tomassoni D, Bronzetti E, Cantalamessa F, Mignini F, Ricci A, Sabbatini M, et al. Postnatal development of dopamine receptor expression in rat peripheral blood lymphocytes. Mechanisms of ageing and development. 2002; 123: 491-8.

36. Kirillova GP, Hrutkay RJ, Shurin MR, Shurin GV, Tourkova IL, Vanyukov MM. Dopamine receptors in human lymphocytes: Radioligand binding and quantitative RT-PCR assays. J Neurosci Methods. 2008; 174: 272-80.

37. Kwak YT, Koo M-S, Choi C-H, Sunwoo I. Change of dopamine receptor mRNA expression in lymphocyte of schizophrenic patients. BMC medical genetics. 2001; 2: 3 .

38. Ilani T, Ben-Shachar D, Strous RD, Mazor M, Sheinkman A, Kotler M, et al. A peripheral marker for schizophrenia: Increased levels of D3 dopamine receptor mRNA in blood lymphocytes. Proceedings of the National Academy of Sciences. 2001; 98: 625-8.

39. Zvara Á, Szekeres G, Janka Z, Kelemen JZ, Cimmer C, Sántha M, et al. Over-expression of dopamine D _2 receptor and inwardly rectifying potassium channel genes in drug-naive schizophrenic peripheral blood lymphocytes as potential diagnostic markers. Disease markers. 2005; 21: 61-9.

40. Ersche KD, Roiser JP, Lucas M, Domenici E, Robbins TW, Bullmore ET. Peripheral biomarkers of cognitive response to dopamine receptor agonist treatment. Psychopharmacology. 2011; 214: 779-89.
41. Goodarzi A, Vousooghi N, Sedaghati M, Mokri A, Zarrindast M-R. Dopamine receptors in human peripheral blood lymphocytes: Changes in mRNA expression in opioid addiction. European journal of pharmacology. 2009; 615: 218-22.

42. Czermak C, Lehofer M, Renger H, Wagner EM, Lemonis L, Rohrhofer A, et al. Dopamine receptor D3 mRNA expression in human lymphocytes is negatively correlated with the personality trait of persistence. Journal of neuroimmunology. 2004; 150: 145-9.

43. Clayton JA, Collins FS. Policy: NIH to balance sex in cell and animal studies. Nature. 2014; 509: 282-3.

\author{
Corresponding author: \\ Li Tao \\ The Psychiatric Laboratory \\ Department of Psychiatry \\ State Key Laboratory of Biotherapy \\ 28 Dian Xin Nan Road \\ West China Hospital \\ Sichuan University \\ Chengdu \\ Sichuan 610041 \\ P R China \\ Tel/Fax: +86-28-85423561 \\ E-mail: xuntao26@hotmail.com
}

